\title{
Radiation Induced Non-targeted Response: Mechanism and Potential Clinical Implications
}

\author{
Tom K. Hei ${ }^{*}$, Hongning Zhou, Yunfei Chai, Brian Ponnaiya, and Vladimir N. Ivanov \\ Center for Radiological Research, Department of Radiation Oncology, College of Physicians and \\ Surgeons, Columbia University Medical Center, New York, USA
}

\begin{abstract}
Generations of students in radiation biology have been taught that heritable biological effects require direct damage to DNA. Radiation-induced non-targeted/bystander effects represent a paradigm shift in our understanding of the radiobiological effects of ionizing radiation in that extranuclear and extracellular effects may also contribute to the biological consequences of exposure to low doses of radiation. Although radiation induced bystander effects have been well documented in a variety of biological systems, including 3D human tissue samples and whole organisms, the mechanism is not known. There is recent evidence that the NF- $\kappa \mathrm{B}$-dependent gene expression of interleukin 8 , interleukin 6 , cyclooxygenase-2, tumor necrosis factor and interleukin 33 in directly irradiated cells produced the cytokines and prostaglandin E2 with autocrine/ paracrine functions, which further activated signaling pathways and induced NF- $\kappa B$-dependent gene expression in bystander cells. The observations that heritable DNA alterations can be propagated to cells many generations after radiation exposure and that bystander cells exhibit genomic instability in ways similar to directly hit cells indicate that the low dose radiation response is a complex interplay of various modulating factors. The potential implication of the non-targeted response in radiation induced secondary cancer is discussed. A better understanding of the mechanism of the non-targeted effects will be invaluable to assess its clinical relevance and ways in which the bystander phenomenon can be manipulated to increase therapeutic gain in radiotherapy.
\end{abstract}

\section{Keywords}

Clinical relevance; cyclooxygenase-2; MAPK signaling; NF- $\mathrm{BB}$; non-targeted/bystander effects; radiation-induced second tumor

\section{INTRODUCTION}

For over a century since the discovery of X-rays, it has always been accepted that the deleterious effects of ionizing radiation such as mutation and carcinogenesis are due mainly to direct damage to DNA. As such, generations of students in radiation biology have been taught that such heritable biological effects are the consequence of a direct radiation-nuclear interaction. With the advances in microbeam technology and the unequivocal demonstration that targeted cytoplasmic irradiation results in mutations in the nuclei of hit cells [1], the concept of extranuclear target of ionizing radiation has since been firmly established. Using a charged particle microbeam, there is clear evidence that cells that are NOT directly

\footnotetext{
(C) 2011 Bentham Science Publishers Ltd.

*Address correspondence to this author at the Center for Radiological Research, Department of Radiation Oncology, Columbia University Medical Center, Vanderbilt Clinic 11-205, 630 West 168th Street, New York, NY 10032, USA; Tel: +1-212-305-8462; Fax: +1-212-305-3229; tkh1@ columbia.ed.
} 
traversed by a particle, but in the vicinity of one that is, or having received signals from such cells, can participate in the damage response [2-4]. This bystander or non-targeted response has clearly delineated the involvement of extracellular targets in radiation damage and has resulted in a paradigm shift in our basic understanding of the target theory of ionizing radiation. In this regard, unique microbeam facilities that can target either cellular nuclei or cytoplasm with a defined number of either protons, photons or a particles with high precision, has played a pivotal role in the advancement of the bystander effect studies $[5,6]$. The demonstration of a bystander effect in 3D human tissues [7] and, more recently, in whole organisms [8] have clear implication of the potential relevance of the non-targeted response to human health. The observations that the progeny of non-targeted cells show an increase in genomic instability as evidenced by an increase in delayed mutations and chromosomal aberrations many generations afterwards [9] indicate the need for a comprehensive assessment of the issue on the bystander effect, particularly among genetically susceptible populations. Thus far, most of the published data on bystander effects have been largely phenomenological in nature. In this report, we will describe the bystander effects mainly from an in vitro aspect and focus on the known mechanisms and signaling pathway involved in the process. Mechanistic-based studies that can provide insight into the nature of the signaling molecule(s) will be invaluable in assessing the clinical relevance of the bystander effect and ways in which the bystander phenomenon can be manipulated to increase therapeutic gain in radiotherapy.

\section{RADIATION-INDUCED NON-TARGETED EFFECTS}

Radiation is a well-established human carcinogen. Based principally on the cancer incidence found in survivors of the atomic bombs in Japan, the International Commission on Radiological Protection (ICRP) and the U.S. National Council on Radiation Protection and Measurements (NCRP) have recommended that estimates of cancer risk for low-dose exposure be extrapolated from higher doses where data are available using a linear, nothreshold model $[10,11]$. This recommendation is based on the dogma that the DNA of the nucleus is the main target for radiation-induced genotoxicity and, since fewer cells are directly damaged at lower doses, the deleterious effects of radiation decline proportionally. However, there is increasing evidence from a number of laboratories indicating that extranuclear targets/extracellular events may also play an important role in determining the biological responses of ionizing radiation, particularly, at low doses (reviewed in $[12,13]$ ). A major conceptual shift in our understanding on the target theory of ionizing radiation in the last decade has resulted from the discovery of the bystander effect.

The radiation-induced bystander effect is defined as the induction of biological effects in cells that are NOT directly traversed by a charged particle, but are in close proximity to cells that are. In Chinese hamster ovary (CHO) cells irradiated with low doses of a-particles where less than $1 \%$ of the cellular nucleus were actually traversed by a particle, an increase in sister chromatid exchanges was observed in over $30 \%$ of the cells [14]. In another words, either cytoplasmic sites or an extracellular component may modulate the observed genotoxic response. The additional responding cells that received no radiation exposure were "bystanders" of either directly hit cells or resulted from agents released from the irradiated medium $[12,15,16]$. While circumstantial evidence in support of a bystander effect appears to be consistent, direct proof of such extranuclear/extracellular effects are most convincingly demonstrated using charged particle microbeams [2-8].

Using microbeam technology, a variety of biological endpoints in both human and other mammalian cell lines have firmly established the presence of a bystander effect under either confluent or sparsely populated culture conditions. In general, as few as one cell in a population that is targeted by a single particle has been shown to be sufficient in eliciting a 
bystander response [17]. Furthermore, increasing the number of particle traversals per cell or the total dose delivered to the irradiated fraction does not increase the intensity of the bystander response. Thus, there is no evidence of a dose response in any of the biological endpoints examined thus far.

The apparent lack of a dose response in bystander effects observed in many in vitro studies conducted using either a microbeam or through medium-mediated approach could have significant, broader implication in radiation risk assessment. The dose response concept and the linear no threshold model form the cornerstone in our current management of radiation risk, particularly at the low dose region. However, at the low dose range, there are other radiobiological effects come into play including adaptive response, genomic instability and genetic susceptibility $[6,12,13,18]$. While the role of bystander effects in human health is not clear at the moment, there is evidence that it may modulate tumor incidence after heavy ion irradiation in mice [19].

\section{MECHANISM OF THE BYSTANDER RESPONSE: GAP JUNCTIONS VERSUS SOLUBLE \\ Mediators}

The plethora of data now available concerning the bystander effect fall into two categories: 1) in confluent cultures where physical contacts between irradiated and non-irradiated cells are made and where gap junctional communications have been shown to be essential for the process; 2 ) in sparsely populated cultures where bystander effects may be mediated by damage signals released into the culture medium by the irradiated cells. As a result, incubation of non-irradiated cells with conditioned medium from irradiated cultures may lead to biological effects in these bystander cells. Since the nature of the signaling molecules involved in the two bystander pathways are not known, their mechanisms are not mutually exclusive at this moment. In fact, it is likely that some common initiating or intermediate steps are involved in the two processes [19].

\section{Gap Junction-Mediated Response}

The relationship between gap junctional activity and radiation-induced bystander mutagenicity was investigated in two ways: 1) the use of chemicals such as octanol and lindane to inhibit gap junction-mediated intercellular communication; and 2) using genetically engineered cells that lack gap junctions. In the first set of studies using microbeam-generated a particles, human-hamster hybrid $\left(\mathrm{A}_{\mathrm{L}}\right)$ cells were treated with a nontoxic, and largely non-mutagenic dose of octanol $(1 \mathrm{mM})$ beginning $2 \mathrm{hr}$ before and up to 3 days after irradiation. Octanol reduced the yield of induced CD59- mutants from $92 \pm 35$ to $16 \pm 3$ per $10^{5}$ survivors [4]. Treatment of octanol alone resulted in a low but detectable mutant fraction of $\sim 10 \pm 4$. In the second set of studies, a three-dimensional cell culture model comprised of $\mathrm{A}_{\mathrm{L}}$ and $\mathrm{CHO}$ cells in multicellular clusters was used to investigate low LET radiation-induced bystander genotoxicity [20]. CHO cells were mixed with $A_{L}$ cells in a 1:5 ratio and centrifuged briefly to produce a spheroid of $4 \times 10^{6}$ cells. $\mathrm{CHO}$ cells were labeled with tritiated thymidine $\left(\left[{ }^{3} \mathrm{H}\right] \mathrm{dTTP}\right)$ for $12 \mathrm{~h}$ and subsequently incubated with $\mathrm{A}_{\mathrm{L}}$ cells for $24 \mathrm{~h}$ at $11^{\circ} \mathrm{C}$. The short-range $\beta$-particles emitted by $\left[{ }^{3} \mathrm{H}\right] \mathrm{dTTP}$ result in selfirradiation of labeled $\mathrm{CHO}$ cells, thus biological effects on neighboring $\mathrm{A}_{\mathrm{L}}$ cells can be attributed to the bystander response. Non-labeled bystander $A_{L}$ cells were isolated from labeled CHO cells using a magnetic separation technique. Treatment of CHO cells with 100 $\mu \mathrm{Ci}\left[{ }^{3} \mathrm{H}\right] \mathrm{dTTP}$ resulted in a 14-fold increase in bystander mutation incidence among neighboring $A_{L}$ cells compared to controls [21]. To demonstrate the functional role of gap junction-mediated signaling response in modulating the bystander effects, cells were pretreated with a $40 \mu \mathrm{M}$ dose of lindane, a well established gap junction inhibitor before the 
clusters were generated. Treatment with lindane significantly reduced the mutation incidence (Fig. (1a)).

Although these results indicate a role of gap junctions in the bystander mutagenic response, octanol and lindane are non-specific inhibitors of gap junctions, and can have wide ranging effects on other cellular structures and functions including membrane fluidity. Therefore, to investigate more specifically the role of gap junction mediated cell-to-cell communication with a particle-induced bystander mutagenicity, it is necessary to use cells in which gap junctional activity was suppressed by a dominant negative connexin construct. Cells containing the dominant negative connexin 43 vector showed little or no bystander mutagenesis [4, 22]. In contrast, cells containing the empty control vector showed little or no suppression of the bystander effect. In this regard, the use of $A_{L}$ cells that are dominant negative for connexin 43 and lack gap junction formation produced a complete attenuation of the bystander mutagenic response (Fig. (1b), [21]). These data clearly show that the connexin 43 vector is working well in the transfected cells and that gap junction-mediated intercellular communication is critical in mediating the bystander mutagenic process.

\section{Medium Transfer-Mediated Bystander Effects}

Earlier studies have shown that medium from an irradiated culture, upon transferal to nonirradiated cells, can induce increased biological effects in the latter. Mothersill and Seymour first demonstrated a highly significant reduction in cloning efficiency in both non-irradiated normal as well as malignant epithelial cell lines that had received medium from ${ }^{60} \mathrm{Co}-\gamma$-ray irradiated cultures [22]. These results suggested that irradiated cells secreted a cytotoxic factor into the culture medium, which was capable of killing non-irradiated cells. Furthermore, transferring medium from low LET-irradiated cultures to un-irradiated cells lead to increased levels of various bystander effects, such as genomic instability [23], cell killing $[24,25]$ and neoplastic transformation [26]. Since the publication of these earlier studies, there have been several adaptations of the medium transfer approaches utilizing a variety of biological endpoints.

To ascertain whether irradiated medium, with or without accompanied cell cultures, can induce bystander genotoxic endpoints in an $\mathrm{A}_{\mathrm{L}}$ cell line, custom-designed double mylar dishes were used. One side (with or without cells, Fig. (2)) was irradiated with a particles using a broad beam from the track segment mode of a $4 \mathrm{MeV}$ Van de Graaff accelerator [27]. Since a particles can only traverse a very limited distance, cells plated on the other side of a medium-filled mylar dish would not be irradiated by the particles. Non-irradiated bystander cells attached to the top mylar layer were found to have a much higher number of chromatid-type aberrations when there was a bottom layer of cells in the medium filled chambers than when just medium alone was present [28]. In fact, very few chromatin fragments were induced in the non-hit bystander cells in the top layer when only medium were irradiated. This increase in bystander chromatid breaks showed a time dependent factor since the incidence increased with increasing incubation period [28]. Furthermore, when transferring the medium from these cell-irradiated dishes to fresh $A_{L}$ cultures, chromatidtype aberrations were produced in the non-irradiated cells. Using the same experimental set up, Zhou et al. found no induction of CD59- mutations but an increase in cytotoxicity conducted under similar experimental conditions [27]. These results suggest that certain yet to be identified excreted factor(s) from the irradiated cells on the bottom mylar layer induce some non-repairable chromosomal changes, resulting in an increased incidence of chromatid breaks. However, there was no increase in mutagenesis presumably as a consequence of an increase in cell death among the putatively mutated, bystander cells.

Using a similarly designed transwell insert, there is evidence that addition of superoxide dismutase and catalase decreases the formation of micronuclei and induction of $\mathrm{p} 21^{\text {Wafl }}$ and 
$\gamma-\mathrm{H} 2 \mathrm{AX}$ foci in bystander normal human fibro-blasts exposed to irradiated medium containing cells [29]. Furthermore, using human glioma cells and a medium transfer approach, there is evidence of the role of the cytokine transforming growth factor beta 1 (TGF- $\beta 1$ ) in the signaling process [30]. However, the nature of the signaling molecule remains elusive.

\section{NATURE OF THE SIGNALING MOLECULES AND PATHWAYS INVOLVED}

In our quest to identify the signaling pathways involved in radiation induced bystander effect, we first focused on the genes that are differentially expressed among the bystander versus control cells. Since the microbeam can only irradiate one cell at a time and a large number of cells are needed for gene array analyses, we employed a novel double mylar dish approach to define the bystander response. Briefly, two concentric stainless steel rings were fitted with mylar bottoms with the outer and inner rings covered by a $6 \mu \mathrm{m}$ - and $38 \mu \mathrm{m}$ thick mylar sheet, respectively. The thicker mylar sheet of the inner ring was sliced into strips. After sterilizing with 70\% ethanol and air-dried, exponentially growing normal human skin fibroblasts were plated in the concentric strip dishes three days before irradiation to ensure a confluent state. Since the fibroblasts seeded on the $38 \mu \mathrm{m}$ thick mylar strips would not be irradiated due to the short penetrating distance of the a particles, these cells would effectively become the bystander cells, being seeded right next to the cells plated on the $6 \mu \mathrm{m}$ mylar dishes that were directly irradiated.

Using a signal transduction pathway specific SuperArray, we compared the differentially expressed genes among the non-irradiated control NHLF cells and the bystander cells. Among the 96 genes represented on the platform, transcription level of one gene, cyclooxygenase-2(COX-2), was found to be consistently up-regulated by more than threefold, while the RNA level of insulin growth factor binding protein-3 (IGFBP3) was found to be consistently lower by more than seven-fold in multiple analyses of multiple bystander samples [30]. Semi-quantitative reverse transcription (RT)-PCR was used to confirm the expression levels of these two genes using expression level of the glyceraldehyde 3-phosphate dehydrogenase (GAPDH) gene as an internal control. The expression of the COX-2 protein in the non-irradiated bystander cells was further confirmed by western blotting. Addition of the COX-2 inhibitor NS-398 $(50 \mu \mathrm{M})$ suppressed COX-2 activity in NHLF cells and finally, after 24 hours, reduced the COX-2 protein level in bystander cells to a non-detectable level [31]. These results indicated that expression of COX-2 is associated with the bystander effect.

\section{Effects of COX-2 Inhibitor on the Bystander Effect}

If the COX-2 gene is causally linked to the bystander signaling pathways, it should be possible to modulate the bystander response using a specific inhibitor of the COX-2 enzymatic activity. Experiments were conducted to show the effect of a non-cytotoxic and non-mutagenic dose of NS-398, a specific inhibitor of COX-2 activity, on bystander mutagenesis at the hypoxanthine guanine phosphoribosyl-transferase (HPRT) locus in NHLF cells irradiated with a 0.5 Gy dose of a particles using the track segment beam [31]. NHLF cells showed a bystander mutagenic yield of $~ 4.2+1.2$ mutants per $10^{6}$ survivors. In contrast, in cultures co-treated with NS-398 $(50 \mu \mathrm{M})$ that did not increase the spontaneous mutant yield by itself, the bystander mutant fraction was reduced by more than six-fold to a level of $\sim 0.7+0.2$ mutants per $10^{6}$ survivors. Although NS-398 treatment was able to reduce the $H P R T^{-}$mutant fraction in the directly irradiated population as well, the magnitude of suppression, from $9.2+3.5$ to $5.9+2.2$ mutants per $10^{6}$ survivors was only $36 \%$. 


\section{Activation of MAPK Signaling Pathways in Bystander Cells}

Insulin growth factor and other cytokines activate mitogen activated protein kinase (MAPK) signaling cascade; and activation of extracellular signal-related kinase (ERK) by phosphorylation is a critical upstream event preceding $C O X-2$ expression. Results of our studies in determining ERK activity by Western blot analysis demonstrated strong upregulation of phospho-ERK levels in both a-irradiated and bystander NHLF $4 \mathrm{~h}$ after treatment [31]. Increased levels of phospho-ERK could even be detected $16 \mathrm{~h}$ after treatment, indicating a persistent response to the bystander signaling. In contrast, activity of MAPK p38 kinase was found to be increased $4 \mathrm{~h}$ after treatment and was not detectable $16 \mathrm{~h}$ after irradiation. It should be noted that when compared with the controls, the ratio of phosphorylated ERK over native ERK increased from 2 to 13 among the bystander cells. To further confirm the activation of ERK in bystander cells, we used PD98059 $(50 \mu \mathrm{M})$, a specific inhibitor of MAP kinase kinases (MEK)-extracellular signal-regulated kinase (ERK), which had been added to cell cultures immediately after irradiation for a period of 4 h. In the presence of PD98059, the phosphorylated form of ERK and its activation were suppressed in both a particle irradiated and bystander cells.

If activation of the MAPK signaling cascade and ERK phosphorylation are essential in mediating the bystander effect, it should be possible to mitigate the later response by using a specific inhibitor of the MEK-ERK signaling cascade. In fact, treatment of cells with a noncytotoxic dose of PD98059 $(50 \mu \mathrm{M})$ completely suppressed bystander toxicity observed in NHLF cultures [31].

\section{A Role for the NF-kB Signaling Pathway and NF-kB-Dependent Gene Expression}

Ionizing irradiation of the cells induces two oppositely directed "information flows" that regulate cell response: from the nucleus to the cytoplasm and from the plasma membrane receptors via the cytoplasm to the nucleus. One of the universal and well documented effects of ionizing radiation is production of double-strand breaks (DSB) in genomic DNA and DSB-induced signaling that targets and activates Ataxia telangiectasia mutated (ATM) kinase in the nucleus followed the initiation of the downstream ATM-mediated signaling pathways [32-34]. ATM-mediated phosphorylation and stabilization of p53 is one of the critical events in directly irradiated cells, which determines cell decision for a growth arrest or to cell death via the mitochondrial apoptotic pathway [35]. A general role of ATM/ATR in the regulation of radiation-induced bystander response was described several years ago and was confirmed by the subsequent investigation [36,-37]. Surprisingly, ATM-p53 signaling axis was not directly involved in the initiation of bystander response [13,38]; furthermore, bystander response was observed for p53-null cells [39].

In contrast and, as shown in Fig. (3), the alternative ATM-mediated pathways of NF- $\mathrm{kB}$, which was initiated at the nucleus, quickly and efficiently induced or upregulated the NF$\kappa \mathrm{B}$-dependent gene expression of numerous "stress" genes [37, 38, 40, 41]. The NF- $\kappa \mathrm{B}-$ dependent gene expression of Interleukin 1 beta (IL1B), IL6, IL8, IL33, tumor necrosis factor(TNF) and PTGS2/COX2, in concert with other NF- $\mathrm{kB}$-target genes, in directly irradiated human skin fibro-blasts resulted in producing the cytokines and their receptors, as well as COX2-dependent prostaglandin E2 (PGE2), with autocrine/paracrine functions. These signaling molecules might further activate signaling pathways and target NF- $\mathrm{BB}$ dependent gene expression in both directly irradiated and non-target cells, using the plasma membrane receptor-initiated pathways through the cytoplasm into the nucleus. For example, the best investigated TNF/TNF-R1 pathway via TRADD/TRAF2/RIP Complex-1 activates Inhibitor $\kappa \mathrm{B}$ Kinase (IKK) complex, which phosphorylates and targets inhibitor of NF- $\kappa \mathrm{B}$ $(\mathrm{I} \kappa \mathrm{B})$ for ubiquitination and proteasome-mediated degradation with the release of the free 
$\mathrm{NF}-\kappa \mathrm{B}$, which after entering into the nucleus specifically regulates gene expression [42, 43]. Additionally, IL1 $\beta$ and IL33 using specific signaling pathways may also activate NF- $\mathrm{KB}$.

On the other hand, NF- $\mathrm{kB}$-dependent expression of IL6 via IL6-receptor complex activates Janus kinase 2 (JAK2)- signal transducer and activator of transcription 3 (STAT3) pathway and STAT3-dependent gene expression, establishing a link between ATM, NF- $\mathrm{kB}$ and STAT3 [44, 45]. Interestingly, STAT3 maintains the constitutive NF- $\ltimes$ B activation by prolonging NF- $\kappa$ B nuclear retention [46]. Importantly, NF- $\kappa$ B and STAT3 control expression of both distinct and overlapping group of genes; the overlapping group contains numerous genes including $\mathrm{COX} 2, \mathrm{Bcl}-2, \mathrm{Bcl}-\mathrm{X}_{L}$, which demonstrate a strong anti-apoptotic activity, and many others [47].

As a result of paracrine functions of cytokines, which were produced by directly irradiated cells, through activation of cytokine-receptors mediated pathways, bystander cells also started expression and production of IL-8, IL-6, COX-2-generated PGE2 and IL-33 followed again by autocrine/paracrine stimulation of the NF- $\kappa B$, MAPK and STAT3 pathways [37]. This creates a positively regulated loop that maintains a permanent cytokine expression. The remarkable feature of the bystander response was its rapid development: even $30 \mathrm{~min}$ after a-irradiation, non-target fibroblasts induced or up-regulated NF- $\kappa B$-dependent expression IL-6 and IL-33, as well as of matrix metalloproteinases 1 and 3; chemokine ligands 2, 3 and 5 in concert with other genes specifically expressed in bystander cells (407 genes, $30 \mathrm{~min}$ after irradiation) [48]. A blockage of TNFa or IL-33 transmitting functions with corresponding monoclonal antibodies added into the culture media decreased NF- $\mathrm{kB}$ activation in both directly irradiated and bystander cells, confirming the existence of the secondary autocrine/paracrine loop regulating NF- $\mathrm{kB}$-dependent gene expression in both irradiated and non-targets cells [37, 41].

\section{A Role for Growth Factor/Growth Factor-Receptor-Mediated Gene Expression}

As shown in Fig. (3), numerous growth factor/growth factor receptor interactions induce receptor tyrosine kinase activities and initiate the corresponding signaling pathways targeting PI3K-AKT and MAPK. Insulin-like growth factor-1 (IGF-1) is permanently present in the cell culture in the complex with IGFBP-3 [49], while gene expression of its ubiquitous receptor (IGF-1R) is under control of NF- $\kappa$ B. IGF-1/IGF-1Receptor kinase activity regulated the phospho-inositide-3-kinase (PI3K)-AKT pathway in both directly irradiated and bystander fibroblasts. However, a pronounced and prolonged increase in AKT activity after irradiation was a characteristic feature of bystander cells [37, 48], probably indicating the preferential presence of the AKT suppressive activity (such as phosphatase and tensin homolog (PTEN)) in directly irradiated fibroblasts. Subsequently, active AKT inactivated GSK3 $\beta$ by phosphorylation of Ser9 [50] that was accompanied by stabilization of $\beta$-catenin protein levels in bystander cells $[36,47]$. $\beta$-catenin/LEF1 complex, as a transcription factor, in concert with NF- $\kappa$ B and STAT3 was involved in transcription regulation of $\mathrm{COX}-2$, one of the critical regulators of inflammation and bystander response [31]. A critical role of COX-2 expression for the regulation of bystander response was discussed above [13]. COX-2-directed production of PTGE2 during bystander response started a new cycle of cell signaling through the correspondent receptors that was accompanied by massive production of reactive oxygen species in bystander cells, further highlighting a similarity between non-target response and inflammation. Besides IGF-1/ IGF-1R signaling pathways, fibroblast growth factor 2 (FGF2)/fibroblast growth factor receptor (FGFR) pathway was activated in both directly irradiated and bystander fibroblasts, targeting the PI3K-AKT and MAPK pathways [47]. 


\section{RADIATION-INDUCED BYSTANDER EFFECTS AND REGULATION OF APOPTOSIS}

AKT, one of the main regulators of the general cell functions, including cell survival, controls general protein synthesis through activation of mammalian target of rapamycin (mTOR), inactivation of pro-apoptotic proteins by phosphorylation, and stabilization of antiapoptotic protein levels [51]. AKT also positively regulated IL-33 protein expression levels [36]. Suppression of the IGF-1R--AKT--IL-33 pathway by picropodophyllin (PPP), a small molecular inhibitor of IGF-1R kinase activity, substantially increased radiation-induced or TNF-related apoptosis-inducing ligand (TRAIL)-induced apoptosis in fibroblasts [36]. Taken together, these results demonstrated the early activation of NF- $\kappa B$-dependent gene expression first in directly irradiated and then bystander fibroblasts, the further modulation of critical proteins, including IL-33, by AKT in bystander cells and late drastic changes in the cell survival and in enhanced sensitivity to TRAIL-induced apoptosis after suppression of the IGF-1R--AKT--IL-33 signaling cascade in both directly irradiated and bystander cells $[37,48]$.

The main task of radiation therapy of cancer is induction of cancer cell death by apoptosis, necrosis or mitotic catastrophe with minimal lethal effects for non-target normal cells. Massive production and release of pro-inflammatory cytokines by directly irradiated cells, besides protective anti-apoptotic effects for these cells, initiate a strong inflammatory response of non-target cells, which may result in different final points, including creation of pathological conditions favorable for further cancer development. Indeed, a close connection between inflammation and cancer development was convincingly demonstrated in the recent years $[43,52]$. The main players of these events, NF- $\kappa B$, IL6 and STAT3, are dramatically involved in the regulation of bystander response. Using anti-inflammatory agents, such as humanized monoclonal inhibitory antibodies against TNFa and IL6, small molecular inhibitors of COX-2 or IGF-1R might be a promising alternative for increasing efficacy of radiotherapy by suppression of the inflammatory response of bystander cells.

\section{POTENTIAL CLINICAL IMPLICATION OF THE NON-TARGETED RESPONSE}

As stated above, there is increasing evidence that cells that are not directly exposed to radiation, but are the progeny of cells that were irradiated many cell divisions previously, may express a high level of gene mutations, cell lethality and chromosome aberration. Collectively, this phenomenon has become known as genomic instability [53]. Genomic instability and the bystander effect have one thing in common, namely that both involve non-targeted effects in non-irradiated cells; in one case, being in the progeny of irradiated cells; and in the other, being in the close neighbors of irradiated cells. The observations that 1) several cell cycle checkpoint genes such as cyclin B1 and RAD51 have been shown to be over-expressed in radiation induced bystander cells [54]; and 2) that DNA repair deficient cells have a higher bystander chromosomal aberration and mutagenic response [55] provide a possible link between genomic instability and bystander response. This link is further strengthened by a variety of in vivo and in vitro studies $[9,12,23,56]$. Since genomic instability is considered a predisposition factor for carcinogenesis, it has been postulated that radiation induced non-targeted/bystander effects may promote secondary cancer induction in radiotherapy patients [57].

From animal studies with X-rays, there is evidence that irradiation of partial of the lung in mice can induce a non-targeted response in the non-irradiated part of the lung through the induction of inflammatory cytokines [58]. With irradiation of the lower region of the lung, the frequency of micronuclei increased in the out-of-field upper lung relative to the shamirradiated group. The induction of micronuclei in the non-targeted lung tissues was inhibited 
by superoxide dismutase (SOD) and L-N ${ }^{G}$-Nitroarginine methyl ester (L-NAME), a nonspecific inhibitor of nitric oxide synthase, which suggested that production of reactive oxygen species and nitric oxide resulted in indirect DNA damage and induced a bystander effect in the neighboring tissue $[59,60]$. Furthermore, there is recent evidence that irradiation of the lower abdomen of mice with X-rays results in the induction of inflammatory response [61] as well as mutations and COX-2 induction [62] in out of field lung tissues.

Using the radiosensitive Patched-1 ${ }^{+/-}\left(\right.$Ptch $\left.^{+/-}\right)$mouse model system that has a defect in radiation-induced activation of the ATR-Chk1 checkpoint signaling pathway [63], Mancuso et al reported induction of medulloblastoma in the non-irradiated brain tissues after partial irradiation of the lower half of the animal with a $3 \mathrm{~Gy}$ dose of X-rays [64]. A significant increase in medulloblastoma (39\%) occurred in the partial body irradiated heterozygous mice compared to the sham-treated group. The study also showed the induction of $\gamma \mathrm{H} 2 \mathrm{AX}$, a marker of DSBs and apoptosis in bystander cerebellum. Although these short-term bystander responses can be detected in different mouse strains after similar treatment, the carcinogenesis in cerebellum was specific for the heterozygous animals and suggested that the endpoints are dependent on the genotype of animals.

Based on human serum analyses, there is clear evidence that plasma clastogenic factors are present many years after radiation exposure from the Japanese atomic bomb survivors, Chernobyl liquidators and from radiotherapy patients [65-68]. To provide a better estimate of the frequency distribution of second primary tumor sites in relation to previous irradiation volumes, a cohort of 115 pediatric patients who developed such cancers were studies [69]. Fig. (4) shows the frequency of second tumors as a function of distance from the irradiation site. It can be estimated that $\sim 22 \%$ of these secondarily derived tumors arise from a distance of at least $5 \mathrm{~cm}$ from the irradiated site and $\sim 6 \%$ arise from a distance that is $>10 \mathrm{~cm}$ away. A peak second primary tumor frequency of $\sim 31 \%$ was identified in volumes receiving less than $2.5 \mathrm{~Gy}$ and a total of $10 \sim 15 \%$ of these tumors are estimated to arise in tissues receiving less than $0.5 \mathrm{~Gy}$ [69]. Although these findings are suggestive, nonetheless, the data highlight the potential of second tumor development outside the treatment field and at much lower dose level.

\section{SUMMARY}

The unequivocal demonstration that targeted cytoplasmic irradiation results in mutations in the nuclei of these cells [1] and the presence of non-targeted effects, results in a paradigm shift in our basic understanding of the target theory and other radiation-induced low dose effects. The demonstration of a bystander effect in 3D human tissue and whole organisms have shown the potential relevance of the non-targeted response in human health. Mechanistic-based studies that can provide insight on the nature of the signaling molecule(s) will be invaluable in assessing the clinical relevance of the bystander effects and ways in which the bystander phenomenon can be manipulated to increase therapeutic gain in radiotherapy.

\section{Acknowledgments}

The work was supported by funding from the National Institutes of Health grants P01-CA 49062, R01-ES 012888, and the NIEHS Center for Environmental Health grant ES 09089. The Radiological Research Accelerator Facility (RARAF) is an NIH supported Resource Center through grant EB-002033 (NIBIB). 


\section{ABBREVIATIONS}

\begin{tabular}{|c|c|}
\hline$\gamma-\mathbf{H} 2 \mathrm{AX}$ & phosphorylated histone $\mathrm{H} 2 \mathrm{AX}$ \\
\hline $\mathbf{A}_{\mathbf{L}}$ & human-hamster hybrid \\
\hline ATM & Ataxia telangiectasia mutated \\
\hline ATR & ATM and Rad3-related \\
\hline Bcl-2 & B-cell leukemia/lymphoma 2 \\
\hline Bcl-X $\mathbf{X}_{\mathbf{L}}$ & BCL2-like 1 \\
\hline Chk1 & Checkpoint kinases 1 \\
\hline CHO & Chinese hamster ovary \\
\hline COX-2 & cyclooxygenase- 2 \\
\hline DSBs & double-strand breaks \\
\hline ERK & extracellular signal-related kinase \\
\hline FGF2 & fibroblast growth factor 2 \\
\hline FGFR & fibroblast growth factor receptor \\
\hline GAPDH & glyceraldehyde 3-phosphate dehydrogenase \\
\hline GSK3 $\beta$ & Glycogen synthase kinase 3 beta \\
\hline HPRT & hypoxanthine guanine phosphoribosyltransferase \\
\hline ICRP & International Commission on Radiological Protection \\
\hline IGFBP3 & insulin growth factor binding protein-3 \\
\hline IGF-1 & Insulin-like growth factor-1 \\
\hline $\mathbf{I} \boldsymbol{K B}$ & inhibitor of NF-kB \\
\hline IKK & Inhibitor $\kappa \mathrm{B}$ Kinase \\
\hline IL1B & Interleukin 1 beta \\
\hline JAK2 & Janus kinase 2 \\
\hline LET & Linear Energy Transfer \\
\hline LEF1 & lymphoid enhancer-binding factor 1 \\
\hline L-NAME & L-N $\mathrm{N}_{-}$-Nitroarginine methyl ester \\
\hline MAPK & mitogen activated protein kinase \\
\hline MEK & MAP kinase kinases \\
\hline NCRP & National Council on Radiation Protection and Measurements \\
\hline $\mathbf{N F}-\kappa \mathbf{B}$ & (Nuclear Factor-KappaB \\
\hline NHLF & Normal Human Lung Fibroblasts \\
\hline PGE2 & prostaglandin E2 \\
\hline PI3K & phosphoinositide-3-kinase \\
\hline PPP & picropodophyllin \\
\hline $\operatorname{Ptch}^{+/-}$ & Patched-1 ${ }^{+/-}$ \\
\hline
\end{tabular}




$\begin{array}{ll}\text { PTEN } & \text { phosphatase and tensin homolog } \\ \text { RARAF } & \text { Radiological Research Accelerator Facility } \\ \text { RIP } & \text { receptor interacting protein } \\ \text { SOD } & \text { superoxide dismutase } \\ \text { STAT3 } & \text { signal transducer and activator of transcription } \\ \text { TGF- } \beta 1 & \text { transforming growth factor beta 1 } \\ \text { TNF } & \text { tumor necrosis factor } \\ \text { TRADD } & \text { TNFRSF1A-associated via death domain } \\ \text { TRAF2 } & \text { TNF receptor-associated factor 2 } \\ \text { TRAIL } & \text { TNF-related apoptosis-inducing ligand }\end{array}$

\section{References}

1. Wu LJ, Randers-Pehrson G, Waldren CA, Geard CR, Yu ZY, Hei TK. Targeted cytoplasmic irradiation by a particles induces gene mutations. Proc Natl Acad Sci USA. 1999; 96:4959-4964. [PubMed: 10220401]

2. Prise KM, Belyakov OV, Folkard M, Michael BD. Studies of bystander effects in human fibroblasts using a charged particle microbeam. Int J Radiat Biol. 1998; 74:793-798. [PubMed: 9881726]

3. Zhou H, Randers-Pehrson G, Waldren CA, Vannais D, Hall EJ, Hei TK. Induction of a bystander mutagenic effect of a particles in mammalian cells. Proc Natl Acad Sci USA. 2000; 97:2099-2104. [PubMed: 10681418]

4. Zhou H, Suzuki M, Randers-Pehrson G, Vannais D, Trosko JE, Waldren CA, Hei TK. Radiation risk at low doses may be greater than we thought. Proc Natl Acad Sci US A. 2001; 98:1441014415.

5. Prise KM, Schettino G, Vojnovic B, Belyakov O, Shao C. Microbeam studies of the bystander response. J Radiat Res. 2009; 50:A1-A6. [PubMed: 19346680]

6. Hei TK, Ballas LK, Brenner DJ, Geard CR. Advances in radiobiological studies using a microbeam. J Radiat Res. 2009; 50:A7-A12. [PubMed: 19346688]

7. Belyakov OV, Mitchell SA, Parikh D, Randers-Pehrson G, Marino SA, Amundson SA, Geard CR, Brenner DJ. Biological effects in unirradiated human tissue induced by radiation damage up to 1 mm away. Proc Natl Acad Sci USA. 2005; 102:14203-14208. [PubMed: 16162670]

8. Bertucci A, Pocock RD, Randers-Pehrons G, Brenner DJ. Microbeam irradiation of the C. elegans nematode. J Radiat Res. 2009; 50:A49-A54. [PubMed: 19346684]

9. Lorimore SA, Chrystal JA, Robinson JI, Coates PJ, Wright EG. Chromosomal instability in unirradiated hematopoietic cells induced by macrophage exposed in vivo to ionizing radiation. Cancer Res. 2008; 68:8122-8126. [PubMed: 18829571]

10. International Commission on Radiological Protection, Recommendations. Report no 60. Pergamon Press; New York: 1990.

11. National Council on Radiation Protection and Measurements. Report 116. NCRP; Bethesda, MD: 1993.

12. Morgan WF. Non-target and delayed effects of exposure to ionizing radiation: I Radiation induced genomic instability and bystander effects in vitro. Radiat Res. 2003; 159:567-580. [PubMed: 12710868]

13. Hei TK, Zhou H, Ivanov VN, Mei H, Lieberman HB, Brenner DJ, Amundson SA, Geard CR. Mechanism of radiation induced bystander effects: a unifying model. J Pharm Pharmacol. 2008; 60:943-950. [PubMed: 18644187]

14. Nagasawa H, Little JB. Induction of sister chromatid exchanges by extremely low doses of a particles. Cancer Res. 1992; 52:6394-6396. [PubMed: 1423287] 
15. Lehnert BE, Goodwin EH. Extracellular factors following exposure to a particles can cause sister chromatid exchanges in normal human cells. Cancer Res. 1997; 57:2164-2171. [PubMed: 9187116]

16. Mothersill C, Seymour CB. Cell-cell contact during $\gamma$-irradiation is not required to induce bystander effect in normal human keratinocytes: evidence for release during irradiation of a signal controlling survival into the medium. Radiat Res. 1998; 149:256-262. [PubMed: 9496888]

17. Shao C, Stewart V, Folkard M, Michael BD, Prise KM. Nitric oxide-mediated signaling in the bystander response of individually targeted glioma cells. Cancer Res. 2003; 63:8437-8442. [PubMed: 14679007]

18. Morgan WF. Communicating non-targeted effects of radiation to achieve adaptive homeostasis in tissues. Curr Mol Pharmacol. 2011; 4:135-140. [PubMed: 21143182]

19. Hamada N, Maeda M, Otsuka K, Tomita M. Signaling pathways underpinning the manifestations of ionizing radiation-induced bystander effects. Curr Mol Pharmacol. 2011; 4:79-95. [PubMed: 21143186]

20. Cucinotta FA, Chappell LJ. Non-targeted effects and the dose response for heavy ion tumor induction. Mutat Res. 2010; 687:49-53. [PubMed: 20085778]

21. Persaud R, Zhou H, Baker SE, Hei TK, Hall EJ. Assessment of low linear energy transfer radiation-induced bystander mutagenesis in a three-dimensional culture model. Cancer Res. 2005; 65:9876-9882. [PubMed: 16267011]

22. Azzam EI, de Toledo SM, Little JB. Direct evidence for the participation of gap junction mediated intercellular communication in the transmission of damage signals from a particle irradiated to non-irradiated cells. Proc Natl Acad Sci USA. 2001; 98:473-478. [PubMed: 11149936]

23. Mothersill C, Seymour C. Delayed expression of lethal mutations and genomic instability in the progeny of human epithelial cells that survived in a bystander-killing environment. Radiat Oncol Investig. 1997; 5:106-110.

24. Lyng FM, Seymour CB, Mothersill C. Production of a signal by irradiated cells which leads to a response in unirradiated cells characteristic of initiation of apoptosis. Br J Cancer. 2000; 83:12231230. [PubMed: 11027437]

25. Nagar S, Smith LE, Morgan WF. Characterization of a novel epigenetic effect of ionizing radiation: the death inducing effect. Cancer Res. 2003; 63:324-328. [PubMed: 12543783]

26. Lewis DA, Mayhugh BM, Qin Y, Trott K, Mendoca MS. Production of delayed death and neoplastic transformation in CGL1 cells by radiation-induced bystander effects. Radiat Res. 2001; 156:251-258. [PubMed: 11500134]

27. Zhou H, Suzuki M, Geard CR, Hei TK. Effects of irradiated medium with or without cells on bystander cell responses. Mutat Res. 2002; 499:135-141. [PubMed: 11827706]

28. Suzuki M, Zhou H, Geard CR, Hei TK. Effect of medium on chromatin damage in bystander mammalian cells. Radiat Res. 2004; 162:264-269. [PubMed: 15332998]

29. Yang J, Asaad N, Held KD. Medium-mediated intercellular communication is involved in bystander response of X-ray-irradiated normal human fibroblasts. Oncogene. 2005; 24:2096-2103. [PubMed: 15688009]

30. Gow MD, Seymour CB, Ryan LA, Mothersill CE. Induction of bystander response in human glioma cells using high energy electrons: role of TGF- $\beta 1$. Radiat Res. 2010; 173:769-778. [PubMed: 20518656]

31. Zhou HN, Ivanov VN, Gillespie J, Geard CR, Amundson SA, Brenner DJ, Yu ZL, Lieberman HB, Hei TK. Mechanism of radiation-induced bystander effects: role of cyclooxygenase 2 signaling pathway. Proc Natl Acad Sci USA. 2005; 102:14641-146465. [PubMed: 16203985]

32. Bakkenist CJ, Kastan MB. DNA damage activates ATM through intermolecular autophosphorylation and dimer dissociation. Nature. 2003; 421:499-506. [PubMed: 12556884]

33. Matsuoka S, Ballif BA, Smogorzewska A, McDonald ER 3rd, Hurov KE, Luo J, Bakalarski CE, Zhao Z, Solimini N, Lerenthal Y, Shiloh Y, Gygi SP, Elledge SJ. ATM and ATR substrate analysis reveals extensive protein networks responsive to DNA damage. Science. 2007; 316:11601166. [PubMed: 17525332]

34. Lee JH, Paull TT. Activation and regulation of ATM kinase activity in response to DNA doublestrand breaks. Oncogene. 2007; 26:7741-7748. [PubMed: 18066086] 
35. Rashi-Elkeles S, Elkon R, Weizman N, Linhart C, Amariglio N, Sternberg G, Rechavi G, Barzilai A, Shamir R, Shiloh Y. Parallel induction of ATM-dependent pro- and antiapoptotic signals in response to ionizing radiation in murine lymphoid tissue. Oncogene. 2006; 25:1584-1592. [PubMed: 16314843]

36. Burdak-Rothkamm S, Rothkamm K, Prise KM. ATM acts downstream of ATR in the DNA damage response signaling of bystander cells. Cancer Res. 2008; 68:7059-7065. [PubMed: 18757420]

37. Ivanov VN, Zhou H, Ghandhi SA, Karasic TB, Yaghoubian B, Amundson SA, Hei TK. Radiationinduced bystander signaling pathways in human fibroblasts: a role for interleukin-33 in the signal transmission. Cell Signal. 2010; 22:1076-1087. [PubMed: 20206688]

38. Ghandhi SA, Yaghoubian B, Amundson SA. Global gene expression analyses of bystander and a particle irradiated normal human lung fibroblasts: synchronous and differential responses. BMC Med Genomics. 2008; 1:63. [PubMed: 19108712]

39. Zhang Y, Zhou J, Held KD, Redmond RW, Prise KM, Liber HL. Deficiencies of double-strand break repair factors and effects on mutagenesis in directly $\gamma$-irradiated and medium-mediated bystander human lymphoblastoid cells. Radiat Res. 2008; 169:197-206. [PubMed: 18220473]

40. Wu ZH, Shi Y, Tibbetts RS, Miyamoto S. Molecular linkage between the kinase ATM and NFkappaB signaling in response to genotoxic stimuli. Science. 2006; 311:1141-1146. [PubMed: 16497931]

41. Zhou H, Ivanov VN, Lien YC, Davidson M, Hei TK. Mitochondrial function and nuclear factorkappaB-mediated signaling in radiation-induced bystander effects. Cancer Res. 2008; 68:22332240. [PubMed: 18381429]

42. Karin M. Nuclear factor-kappaB in cancer development and progression. Nature. 2006; 441:431436. [PubMed: 16724054]

43. Karin M, Yamamoto Y, Wang QM. The IKK NF-kappa B system: a treasure trove for drug development. Nat Rev Drug Discov. 2004; 3:17-26. [PubMed: 14708018]

44. Yu H, Pardoll D, Jove R. STATs in cancer inflammation and immunity: a leading role for STAT3. Nat Rev Cancer. 2009; 9:798-809. [PubMed: 19851315]

45. Ivanov VN, Zhou H, Partridge MA, Hei TK. Inhibition of ataxia telangiectasia mutated kinase activity enhances TRAIL-mediated apoptosis in human melanoma cells. Cancer Res. 2009; 69:3510-3519. [PubMed: 19351839]

46. Lee H, Herrmann A, Deng JH, Kujawski M, Niu G, Li Z, Forman S, Jove R, Pardoll DM, Yu H. Persistently activated Stat 3 maintains constitutive NF-kappaB activity in tumors. Cancer Cell. 2009; 15:283-293. [PubMed: 19345327]

47. Grivennikov SI, Karin M. Dangerous liaisons: STAT3 and NF-kappaB collaboration and crosstalk in cancer. Cytokine Growth Factor Rev. 2009; 21:11-19. [PubMed: 20018552]

48. Ghandhi SA, Ming L, Ivanov VN, Hei TK, Amundson SA. Regulation of early signaling and gene expression in the a-particle and bystander response of IMR-90 human fibroblasts. BMC Med Genomics. 2010; 3:31. [PubMed: 20670442]

49. Neuhouser ML, Schenk J, Song YJ, Tangen CM, Goodman PJ, Pollak M, Penson DF, Thompson IM, Kristal AR. Insulin-like growth factor-I, insulin-like growth factor binding protein-3 and risk of benign prostate hyperplasia in the prostate cancer prevention trial. Prostate. 2008; 68:14771486. [PubMed: 18618736]

50. Franke TF. PI3K/Akt: getting it right matters. Oncogene. 2008; 27:6473-6488. [PubMed: 18955974]

51. Vivanco I, Sawyers CL. The phosphatidylinositol 3-Kinase AKT pathway in human cancer. Nat Rev Cancer. 2002; 2:489-501. [PubMed: 12094235]

52. Grivennikov S, Karin E, Terzic J, Mucida D, Yu GY, Vallabhapurapu S, Scheller J, Rose-John S, Cheroutre H, Eckmann L, Karin M. IL-6 and Stat3 are required for survival of intestinal epithelial cells and development of colitis-associated cancer. Cancer Cell. 2009; 15:103-113. [PubMed: 19185845]

53. Morgan WF, Sowa MB. Non-targeted bystander effects induced by ionizing radiation. Mutat Res. 2007; 616:159-64. [PubMed: 17134726] 
54. Azzam EI, de Toledo SM, Gooding T, Little JB. Intercellular communication is involved in the bystander regulation of gene expression in human cells exposed to very low fluences of a particles. Radiat Res. 1998; 150:97-504.

55. Nagasawa H, Huo L, Little JB. Increased bystander mutagenic effect in DNA double-strand break repair-deficient mammalian cells. Int J Radiat Biol. 2003; 79:35-41. [PubMed: 12556329]

56. Ponnaiya B, Jenkins-Baker G, Bigelow A, Marino S, Geard CR. Detection of chromosomal instability in a-irradiated and bystander human fibroblasts. Mutat Res. 2004; 568:41-48. [PubMed: 15530538]

57. Sigurdson AJ, Jones IM. Second cancers after radiotherapy: any evidence for radiation-induced genomic instability. Oncogene. 2003; 22:7018-7027. [PubMed: 14557806]

58. Khan MA, Vandyk J, Yeung IW, Hill RP. Partial volume rat lung irradiation; assessment of early DNA damage in different lung regions and effect of radical scavengers. Radiother Oncol. 2003; 66:95-102. [PubMed: 12559526]

59. Calveley VL, Khan MA, Yeung IW, Vandyk J, Hill RP. Partial volume rat lung irradiation: temporal fluctuations of infield and out-of-field DNA damage and inflammatory cytokines following irradiation. Int J Radiat Biol. 2005; 81:887-899. [PubMed: 16524844]

60. Matsumoto H, Tomita M, Otsuka K, Hatashita M, Hamada N. Nitric oxide is a key molecule serving as a bridge between radiation-induced bystander and adaptive responses. Curr Mol Pharmacol. 2011; 4:126-134. [PubMed: 21143183]

61. Van der Meeren A, Monti P, Vandamme M, Squiban C, Wysocki J, Griffiths N. Abdominal radiation exposure elicits inflammatory responses and abscopal effects in the lungs of mice. Radiat Res. 2005; 163:144-152. [PubMed: 15658889]

62. Chai Y, Hei TK. Radiation induced bystander mutagenesis in the gpt delta transgenic mouse model. Proceedings of Radiation Research Society Meeting. 2009:S802.

63. Leonard JM, Ye H, Wetmore C, Karnitz LM. Sonic Hedgehog signaling impairs ionizing radiation induced checkpoint activation and induces genomic instability. J Cell Biol. 2008; 183:385-391. [PubMed: 18955550]

64. Mancuso M, Pasquali E, Leonardi S, Tanori M, Rebessi S, Di Majo V, Pazzaglia S, Toni MP, Pimpinella M, Covelli V, Saran A. Oncogenic bystander radiation effects in Patched heterozygous mouse cerebellum. Proc Natl Acad Sci USA. 2008; 105:12445-12450. [PubMed: 18711141]

65. Emerit I, Levy A, Cernjavski L, Arutyunyan R, Oganesyan N, Pogosian A, Mejlumian J, Sarkisian T, Gulkandanian M, Quastel M, Goldsmith J, Riklis E, Kordysh E, Poliak S, Merklin L. Transferable clastogenic activities in plasma from person exposed as salvage personnel of the Chernobyl reactor. J Cancer Res Clin Oncol. 1994; 120:558-561. [PubMed: 8045922]

66. Emerit I, Quastel M, Goldsmith J, Merkin L, Levy A, Cernjavski L, Alaoui-Youssefi A, Pogossian A, Riklis E. Clastogenic factors in the plasma of children exposed at Chernobyl. Mutat Res. 1997; 373:47-54. [PubMed: 9015152]

67. Pant GS, Kamada N. Chromsomal aberrations in normal leukocytes induced by the plasma of exposed individuals. Hiroshima J Med Sci. 1977; 26:149-154. [PubMed: 591380]

68. Goh KO. Total body irradiation and human chromosomes. Cytogenetic study of peripheral blood and bone marrow leukocytes even years after total body irradiation. Radiat Res. 1968; 35:155170. [PubMed: 5659667]

69. Diallo I, Haddy N, Adjadj E, Samand A, Quiniou E, Chavaudra J, Alziar I, Perret N, Guerin S, Lefkopoulos D, de Vathaire F. Frequency distribution of second solid cancer locations in relation to the irradiated volume among 115 patients treated for childhood cancer. Int J Radiat Oncol Biol Phys. 2009; 74:876-883. [PubMed: 19386434] 


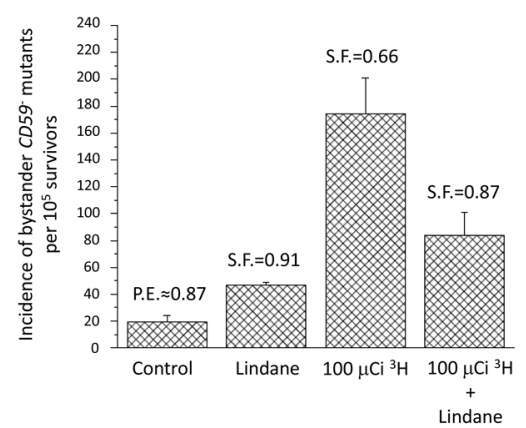

(a)

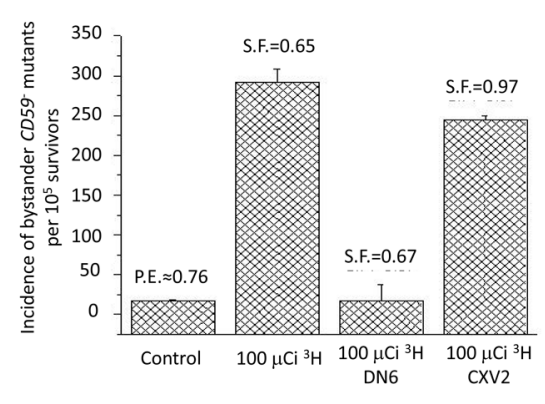

(b)

Fig. 1.

Demonstration of the functional role of gap junctions in bystander mutagenesis in the human hamster hybrid $\left(\mathrm{A}_{\mathrm{L}}\right)$ cells. (a) Effects of Lindane $(40 \mu \mathrm{M})$ on the incidence of CD59mutants among $A_{L}$ cells in cluster with $\mathrm{CHO}$ cells exposed previously to $100 \mu \mathrm{Ci}$ $\left[{ }^{3} \mathrm{H}\right] \mathrm{dTTP}$. (b) Incidence of bystander CD59- mutants among connexin 43-deficient $\mathrm{A}_{\mathrm{L}}$ cells (DN6) and empty vector-transfected $\mathrm{A}_{\mathrm{L}}$ cells (CXV2) clustered with $\mathrm{CHO}$ cells that were either labeled with $100 \mu \mathrm{Ci}\left[{ }^{3} \mathrm{H}\right] \mathrm{dTTP}$ or no labeling (reproduced with permission from [21]). S.F., surviving fraction. P.E., plating efficiency. 


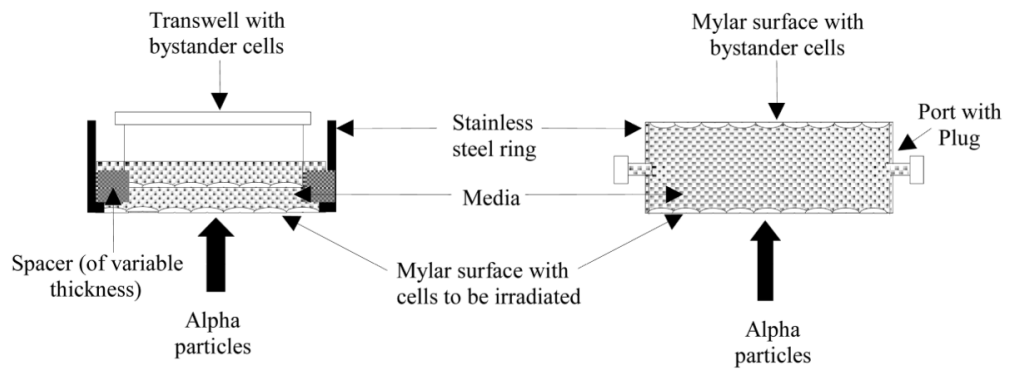

Fig. 2.

Use of mylar dishes or transwells in the study of medium-mediated bystander effect. In the transwell design, cells in a six well tissue culture plate are irradiated and a transwell culture insert dish with a porous bottom seeded with cells is put into the well and incubated to allow the passage of molecule from the irradiated culture to come into contact with the nonirradiated cells seeded on the insert dish. In the double mylar design, both sides of the stainless ring are epoxied with a $6 \mu \mathrm{m}$ mylar and seeded with cells. Since alpha particles have a limited penetrance in liquid, cells seeded on the bottom mylar layer are irradiated while those on the top layer are effectively the bystander cells. 


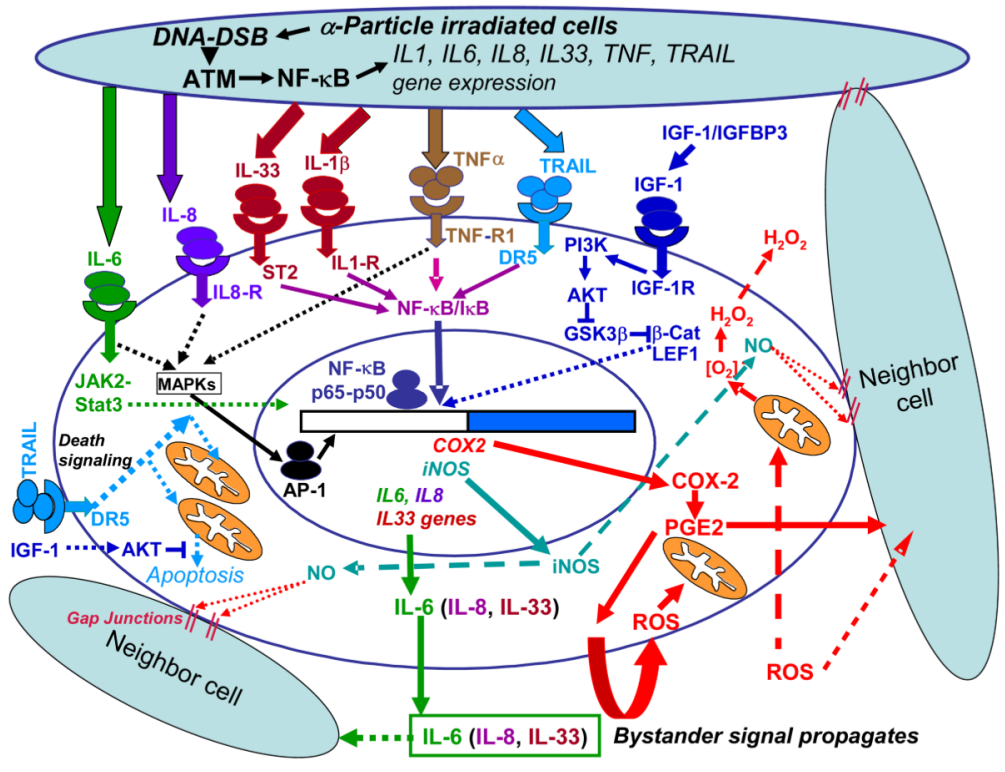

Fig. 3.

A model of the signaling pathways regulating radiation-induced bystander effects through expression and secretion of soluble biologically active factors. $a$-particle irradiation caused DNA damage, which induces ATM activation in normal and cancer cells. ATM further activates the NF- $\mathrm{KB}$ pathway, which targets gene expression of numerous cytokines and $C O X 2$. Cytokines initiate specific signaling pathways in directly irradiated and bystander cells resulting in the secondary activation of IKK-NF- $\kappa$ B, JAK2-STAT3 and the MAPK pathways with the subsequent induction of cytokine, $C O X 2$ and inducible Nitric Oxide Synthase (iNOS) gene expression. COX-2-produced PGE2 is involved in regulation of reactive oxygen species (ROS) production, iNOS controls synthesis of NO. Effects of ROS and Nitric oxide (NO) in the mitochondrial damage and bystander response were previously described [36]. On the other hand, NF- $\mathrm{B}$ regulates expression of numerous genes controlling a general cell survival and anti-apoptotic activity. Exogenous IGF-1 via ligation of IGF-1R activates the PI3K-AKT pathway that using suppression of GSK3 $\beta$ stabilizes $\beta$ catenin protein levels; LEF1-- $\beta$-catenin heterodimer goes to the nucleus and further controls gene expression. Furthermore, AKT controls numerous general metabolic, survival and antiapoptotic functions in the cell. IGFBP-3 stabilizes the exogenous IGF-1 and extends its action time further activating the basal PI3K-AKT pathway. An additional level of cell-cell communications is a usage of gap junctions that could transmit signaling molecules, such as NO. 


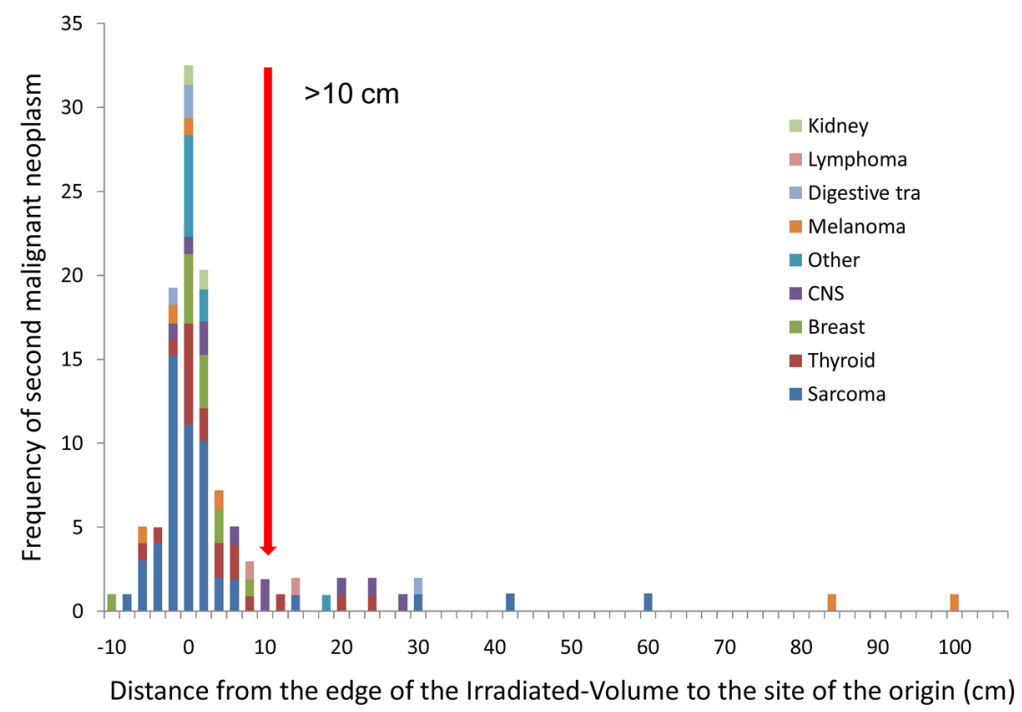

Fig. 4.

Frequency of second primary tumor among 115 pediatric patients among a cohort of 4581 treated with radiation for various primary solid tumors (reproduced with permission from [65]). 